\title{
The Prevalence of Hypothyroidism in Patients with Metabolic Syndrome in Saudi Community Based Hospital: A Retrospective Single Centre Study
}

Khalid S Aljabri, MD, FRCPC, FACP1, Ibrahim M Alnasser, MD, Facharatz², Samia A Bokhari, MD, SBEM ${ }^{1}$, Muneera A Alshareef, MD, SBIM ${ }^{1}$, Patan $M$ Khan, MD, MRCP1, Abdulla M Mallosho, MD ${ }^{1}$,

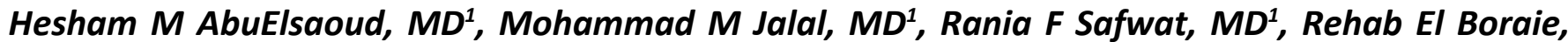
$M D^{1}$, Nawaf $K$ Aljabri, MLT', Waleed $O$ Bawzeer, MD ${ }^{1}$, Mohammad A Melibari, MD', Bandari $K$ Aljabri, MS ${ }^{4}$, Arwa Y Alsuraihi, $\mathrm{MS}^{4}$ and Amjad I Hawsawi, $\mathrm{MS}^{4}$

${ }^{1}$ Department of Endocrinology, King Fahad Armed Forces Hospital, Jeddah, Kingdom of Saudi Arabia ${ }^{2}$ Department of Radiology, King Fahad Armed Forces Hospital, Jeddah, Kingdom of Saudi Arabia ${ }^{3}$ Department of Laboratory, Northern Armed Forces Hospital, Haffr Albatin, Kingdom of Saudi Arabia ${ }^{4}$ College of Medicine, Umm Al Qura University, Makkah, Kingdom of Saudi Arabia

*Corresponding author: Khalid S Aljabri, MD, FRCPC, FRCPC (Endo), FACP, ABIM, ABEM, Department of Endocrinology, King Fahad Armed Forces Hospital, Jeddah, PO Box 9862, Jeddah 21159, Kingdom of Saudi Arabia, Tel: +9662323333 ext. 59200
Abstract
Background and objective: The burden of thyroid diseases in the general population and patients with Metabolic syndrome (MetS) is enormous. To estimate retrospectively the prevalence of hypothyroidism in patients with MetS in Saudi community based hospital.
Design: We analyzed retrospectively 3632 participants whom are between the age 18 to 105 years. All patients were from the population of the Primary health centre at King Fahad Armed Forces Hospital, Jeddah, Saudi Arabia. All data were collected on the basis of a review of electronic medical data. Patients with thyroid stimulating hormone (TSH) above the normal range of TSH for our laboratory reference, history of hypothyroidism and taking thyroid replacement therapy were included. Metabolic risk factors were defined using the 2006 IDF criteria. The total number of cohort were separated on basis of age values into four groups: < 40 years, $40-49$ years, 50-59 years and $\geq 60$ years.
Results: 3632 subjects were included. There were 830 $(22.9 \%)$ male and $2802(77.1 \%)$ were female with mean age $44.4 \pm 15.6$. Hypothyroidism was present in 684 (18.8\%). The mean TSH and FT4 values were $3.3 \pm 5.4 \mathrm{mlU} / \mathrm{l}$ and $15.0 \pm 3.0 \mathrm{pmol} / / \mathrm{respectively.} \mathrm{There} \mathrm{were} 1556$ (42.8\%)

cases with MetS where female was 1130 (72.6\%) and male was $426(27.4 \%)$ with male to female ratio of 1 to $2.6, \mathrm{p}<0.0001$, Table 1. Cases with hypothyroidism were significantly more prevalent in patients with MetS, 21.8 vs. $16.6 \%, p<0.0001$. Regression analysis of odd ratio of risk factors for patients with MetS showed that age and presence of hypothyroidism were associated with higher likely hood of MetS, $(\mathrm{OR}=1.095 ; 95 \%$ confidence interval $[C l]=1.088,1.101), p<0.0001)$ and $(O R=1.301 ; 95 \%$ $\mathrm{Cl}=1.064,1.589), \mathrm{p}=0.01$ ) respectively. Hypothyroidism was significantly more prevalent in all decades $(p<0.0001)$ and non-significantly higher across each age groups. Hypothyroidism was non-significantly more prevalent in females below the age 60 years.

Conclusion: The prevalence of hypothyroidism was high in the patients with MetS. The majority of our patients with primary hypothyroidism were old and predominantly females.

\section{Keywords}

Hypothyroidism, Metabolic syndrome, Saudi Arabia

Citation: Aljabri KS, Alnasser IM, Bokhari SA, Alshareef MA, Khan PM, et al. (2019) The Prevalence of Hypothyroidism in Patients with Metabolic Syndrome in Saudi Community Based Hospital: A Retrospective Single Centre Study. Int J Diabetes Clin Res 6:103. doi.org/10.23937/2377-3634/1410103 Accepted: March 19, 2019: Published: March 21, 2019

Copyright: (c) 2019 Aljabri KS, et al. This is an open-access article distributed under the terms of the Creative Commons Attribution License, which permits unrestricted use, distribution, and reproduction in any medium, provided the original author and source are credited. 


\section{Introduction}

Metabolic Syndrome (MetS) refers to a cluster of cardiovascular risk factors, whose underlying pathophysiology is thought to be related to Insulin Resistance [1-5]. Thyroid gland is one of the important organ in human body and the burden of thyroid diseases in the general population is enormous specially in females $[6,7]$. Thyroid dysfunctions have increased recently and are considered the commonest endocrine diseases [8].

Thyroid function regulates a wide array of metabolic parameters. Thyroid function significantly affects lipoprotein metabolism as well as some cardiovascular disease risk factors. Hypothyroidism is characterized by impaired glucose absorption from the gastrointestinal tract and delayed peripheral glucose assimilation and gluconeogenesis, decreased or normal hepatic glucose output and decreased peripheral tissue glucose disposal. A cross sectional study revealed that even in the euthyroid state low thyroid function predisposes to higher cholesterol, glucose, insulin and insulin resistance [9]. Hypothyroidism has been associated with insulin resistance due to various mechanisms such as altered insulin secretion and lipid levels [10]. Hypothyroidism is characterized by attenuated basal plasma insulin and insulin sensitivity $[11,12]$.

Many studies have analyzed the relationship between the MetS and hypothyroidism, but the results are ambiguous [13]. Metabolic syndrome is increased in patients with hypothyroidism and suggested that hypothyroidism be considered in newly diagnosed MetS patients [14]. The correlation between hypothyroidism and Mets and its components varies in different studies and seems to be influenced by age, gender and race of study participants $[9,15,16]$. A significant correlation between hypothyroidism and Mets was reported in a study from India [17]. Park, et al. found that the serum concentration of TSH in menopausal women with hypothyroidism ew11 was a powerful predictor of Mets and its components [18]. However, in contrast to these studies, the prevalence of Mets among Turkish subjects with subclinical thyroid disorders was similar to normal subjects $(0.35 \%$ compared with $0.33 \%)$ [19].
Epidemiological studies of hypothyroidism have limitations [20]. Therefore, the aim of this study was to investigate the prevalence of the hypothyroidism in Mets in the population of Saudi Arabia.

\section{Methods}

We analyzed retrospectively 3632 participants whom are between the age 18 to 105 years. All patients were from the population of the Primary health centre at King Fahad Armed Forces Hospital, Jeddah, Saudi Arabia. All data were collected randomly on the basis of a review of electronic medical data including clinical data and laboratory tests. Patients with TSH above the normal range of TSH for our laboratory reference, history of hypothyroidism and taking thyroid replacement therapy were included as a diagnosis for hypothyroidism. Patient who are pregnant were excluded. The reference range values of TSH 0.22-4.2 MIU/L, Free T4 12.0-22.0 $\mathrm{pmol} / \mathrm{L}$. Metabolic risk factors were defined using the 2006 IDF criteria that define elevated triglyceride as $\geq$ $150 \mathrm{mg} / \mathrm{dL}$ ( $\geq 1.7 \mathrm{mmol} / \mathrm{L}$ ) and reduced $\mathrm{HDL}$ as $<40 \mathrm{mg} /$ $\mathrm{dL}(<1.03 \mathrm{mmol} / \mathrm{L})$ for male and as $<50 \mathrm{mg} / \mathrm{dL}(<1.29$ $\mathrm{mmol} / \mathrm{L}$ ) for female [21]. HTN was defined when the systolic blood pressure was $\geq 130 \mathrm{mmHg}$ and/or diastolic blood pressure was $\geq 85 \mathrm{mmHg}$ in addition to receiving any medication for hypertension. Abnormal glucose metabolism was considered when HbA1c $(\geq 5.7)$ or when patients were known to have type 2 diabetes. The total number of cohort were separated on basis of age values into four groups: < 40 years, $40-49$ years, 50-59 years and $\geq 60$ years. The study was approved by Ethical Review Committee for Research in Human Subjects.

\section{Statistical Analysis}

Continuous variables were described using means and Standard Deviations. Univariate analysis of baseline demography both between groups, were accomplished using unpaired t-test and nonparametric and Chi square test were used for categorical data comparison. Regression analysis for patients with MetS was performed to assess for odd ratio (OR). Age, gender and hypothyroidism were included in the analysis. P value < 0.05 indicates significance. The statistical analysis was conducted with SPSS version 23.0 for Windows.

Table 1: Base line characteristic and comparison between patients with and without metabolic syndrome [mean \pm standard deviation or number $(\%)]$.

\begin{tabular}{|c|c|c|c|c|c|}
\hline \multirow{2}{*}{\multicolumn{2}{|c|}{ Parameters }} & \multirow[b]{2}{*}{$\begin{array}{l}\text { Total } \\
(3632)\end{array}$} & \multicolumn{2}{|c|}{ Metabolic syndrome } & \multirow[b]{2}{*}{$P$ value } \\
\hline & & & $\begin{array}{l}\text { Present } \\
1556(42.8)\end{array}$ & $\begin{array}{l}\text { Absent } \\
2076(57.2)\end{array}$ & \\
\hline \multicolumn{2}{|c|}{ Age (years) } & $44.4 \pm 15.6$ & $54.1 \pm 12.8$ & $37.1 \pm 13.3$ & $<0.0001$ \\
\hline \multirow{2}{*}{ Gender } & Male & $830(22.9)$ & $426(27.4)$ & $404(19.5)$ & \multirow{2}{*}{$<0.0001$} \\
\hline & Female & 2802 (77.1) & $1130(72.6)$ & $1672(80.5)$ & \\
\hline \multicolumn{2}{|c|}{ Hypothyroidism } & $684(18.8)$ & $339(21.8)$ & $345(16.6)$ & $<0.0001$ \\
\hline \multicolumn{2}{|c|}{ TSH (mlU/l) } & $3.3 \pm 5.4$ & $3.4 \pm 5.6$ & $3.1 \pm 5.3$ & 0.1 \\
\hline \multicolumn{2}{|c|}{ FT4 (pmol/l) } & $15.0 \pm 3.0$ & $15.1 \pm 2.9$ & $141.9 \pm 3.1$ & 0.3 \\
\hline
\end{tabular}




\section{Results}

3632 subjects were included. There were 830 (22.9\%) male and 2802 (77.1\%) were female with mean age $44.4 \pm 15.6$, Table 1 . Hypothyroidism was present in $684(18.8 \%)$. The mean TSH and FT4 values were 3.3 $\pm 5.4 \mathrm{mIU} / \mathrm{l}$ and $15.0 \pm 3.0 \mathrm{pmol} / \mathrm{l}$ respectively. There were $1556(42.8 \%)$ cases with MetS where female was $1130(72.6 \%)$ and male was $426(27.4 \%)$ with male to female ratio of 1 to $2.6, p<0.0001$, Table 1 . Cases with hypothyroidism were significantly more prevalent in patients with MetS, 21.8 vs. $16.6 \%$, p < 0.0001 . Regression analysis of odd ratio of risk factors for patients with MetS showed that age and presence of hypothyroidism were associated with higher likely hood of MetS, $(O R=1.095 ; 95 \%$ confidence interval $[\mathrm{Cl}]=1.088,1.101), \mathrm{p}<0.0001)$ and $(\mathrm{OR}=1.301 ; 95 \%$ $\mathrm{Cl}=1.064,1.589), \mathrm{p}=0.01$ ) respectively, Table 2 . Hypothyroidism was significantly more prevalent in all decades $(p<0.0001)$ and non-significantly higher across each age groups, Figure 1 . Hypothyroidism was nonsignificantly more prevalent in females below the age 60 years, Figure 2.

Table 2: Regression analysis for odd ratio of risk factors for patients with metabolic syndrome.

\begin{tabular}{|l|l|l|}
\hline Parameters & Odd Ratio & P value \\
\hline Male gender & $0.947(0.782-1.140)$ & 0.6 \\
\hline Age (years) & $1.095(1.088-1.101)$ & $<0.0001$ \\
\hline Hypothyroidism & $1.301(1.064-1.589)$ & 0.01 \\
\hline
\end{tabular}

\section{Discussion}

In the present population-based study of 3632 cases, we found an evidence of association between hypothyroidism and the prevalence of Mets. We found $18.8 \%$ of the study population presented with hypothyroidism. Our results $(18.8 \%)$ are higher than previous studies showing an association between hypothyroidism and MetS [5,22-24]. A study done by Meher LK, et al. showed a prevalence of hypothyroidism $(4 \%)$ in the MetS subjects [22]. In addition, similar study from India has shown a prevalence of hypothyroidism (7.4\%) in patients with MetS [5]. A recent study in Taiwan by Wang JY, et al. reported that thyroid dysfunctions were present in $7.2 \%$ of Taiwan MetS patients [23]. Two studies from Nepal had shown the prevalence of hypothyroidism were $1.7 \%$ and $4.6 \%[24,25]$. Sat Byul Park, et al. a study done in Korean population considered 594 patients with metabolic syndrome, hypothyroidism was found in $6.4 \%$ [13].

Among the study population, the prevalence of hypothyroidism related MetS is more in female in agreement with earlier studies $[19,26]$. Moreover, we found that patients with age more than 60 years had a higher prevalence of hypothyroidism as compared to other age groups. Chih Cheng Lai, et al. studied the prevalence of hypothyroidism and its association with MetS in elderly Taiwan people. This study showed that $32 \%$ subjects with hypothyroidism had MetS [27]. Chih Yuan Wang, et al. in his study done at Taiwan university hospital, had included 9055 subjects. The results of this

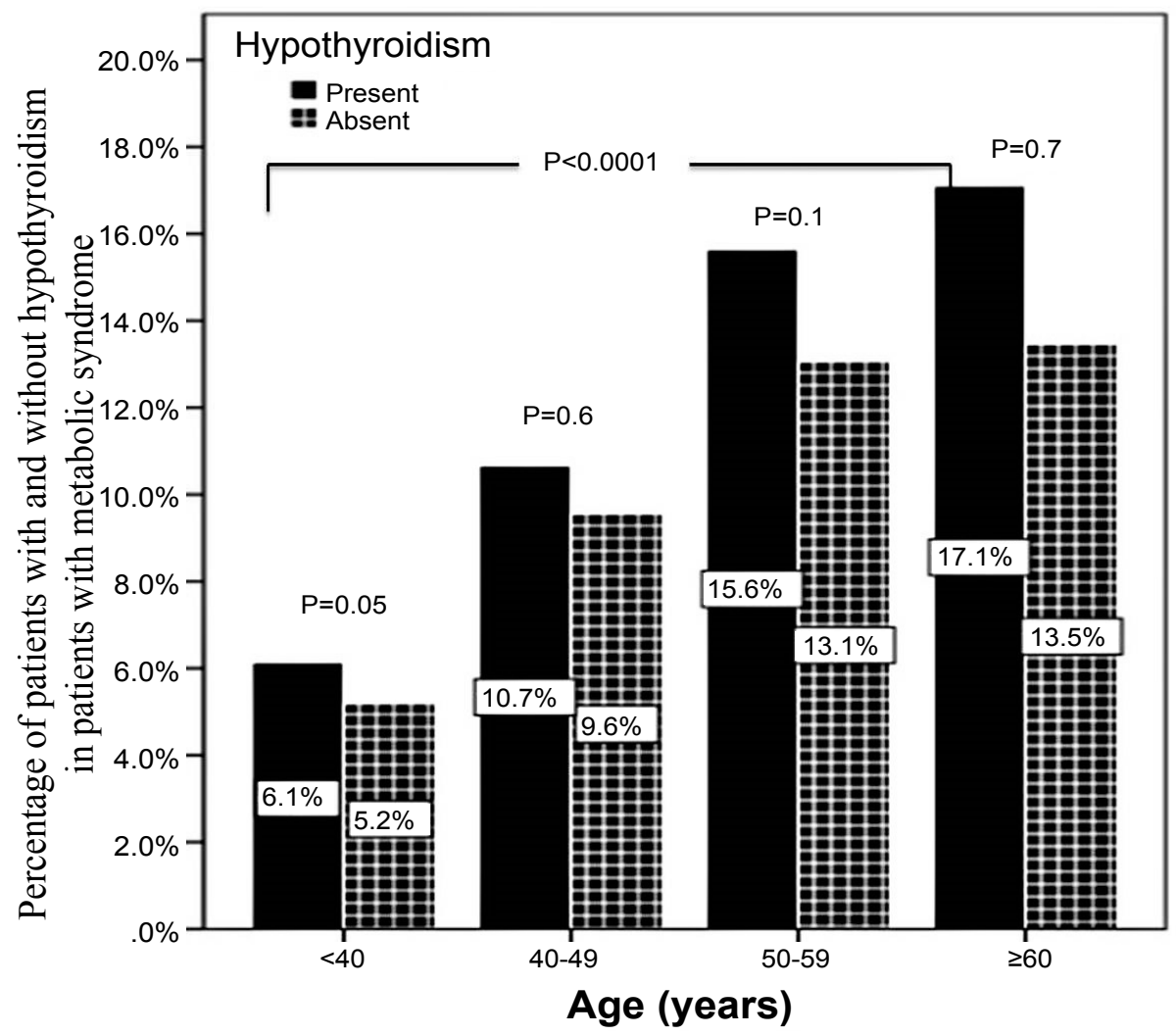

Figure 1: Frequency of hypothyroidism in patients with metabolic syndrome in correlation to age groups. 


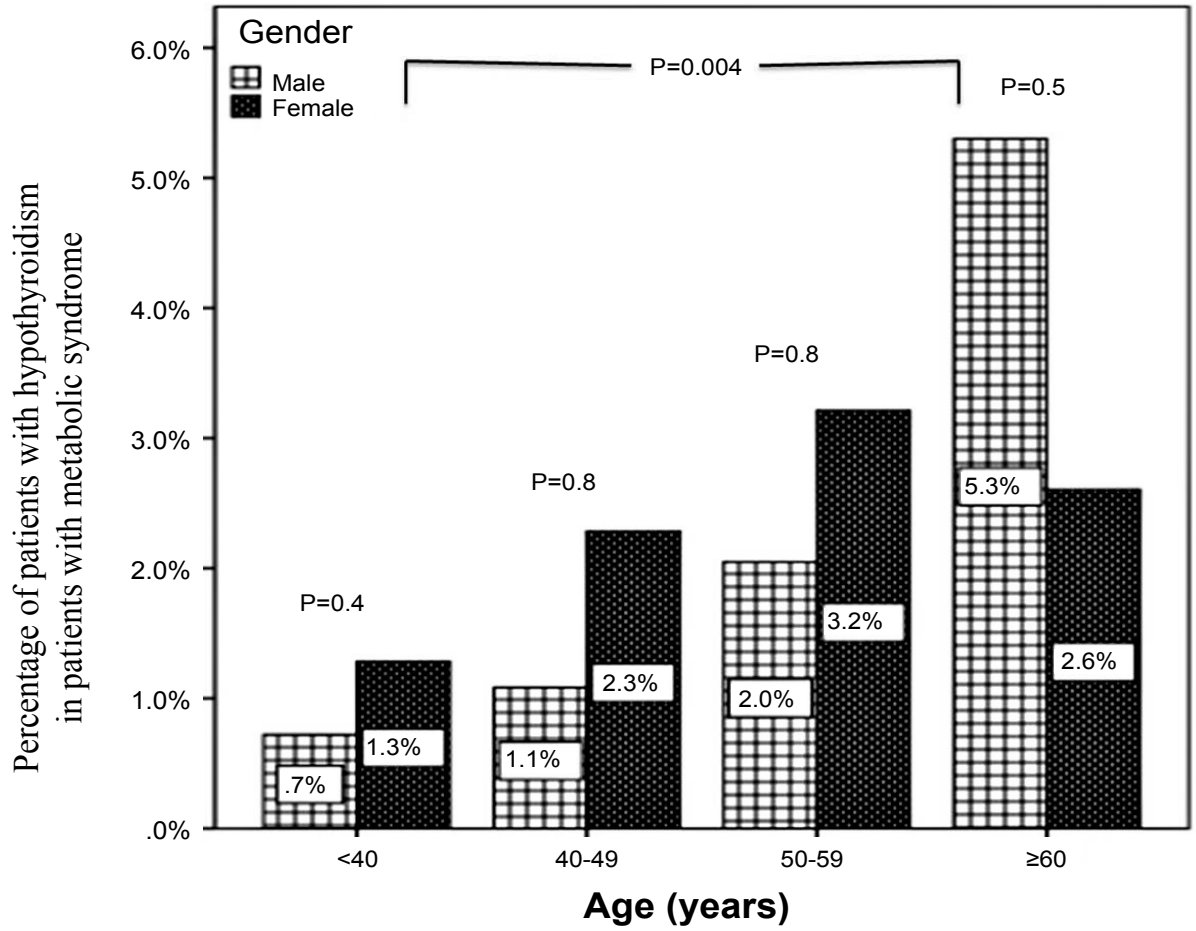

Figure 2: Frequency of hypothyroidism in patients with metabolic syndrome in correlation to age groups and gender.

study showed that there is no statistical correlation between MetS and hypothyroidism [28]. Tehrani, et al. in his population bases study enrolled 914 women with hypothyroidism, of this $19.2 \%$ had hypothyroidism which is lower than our finding (77.6\%) [29]. Gaurav, et al. in a study done in south Indian women included 76 patients with MetS, of which $53 \%$ had hypothyroidism [26]. Shresta, et al. studied the association of MetS association with thyroid abnormalities in 48 females from Nepal. $32 \%$ of the study population had MetS [30]. Of which, the prevalence of MetS was more common in the euthyroid group compared to the hypothyroid group. This study stated that the thyroid dysfunction might be protective for the development of MetS, which contradicted our study.

The frequency of hypothyroidism varies among communities [31]. It is known that hypothyroidism affects MetS parameters via various metabolic changes [32]. However, the associations between hypothyroidism and MetS are well described; people with high TSH levels have more than two times the risk of developing MetS [33]. We found the risk of MetS in the presence of hypothyroidism was increased significantly by $30 \%$.

We aimed to identify the frequency of hypothyroidism in patients in primary health care setting. Furthermore, due to the retrospective nature of this study, the observed population reflects a selected yet comprehensive group of patients rather than the general population. Our study could be limited by the question of clustering of cases within the study region and the effect that might have on our estimates, in addition, the current study population may appear limited in size and therefore may underestimate the true frequency of hypothyroidism in the general population. In addition, the study shares the limitations of all retrospective studies.

In conclusion, the prevalence of hypothyroidism was high in the patients with MetS. The majority of our patients with primary hypothyroidism were old and predominantly females. These two observations remain to be validated by population-based studies. In the absence of registry data, larger cooperative studies involving diverse population samples from multiple centers could help to provide further information on the true frequency nationally.

\section{Acknowledgement}

The author would like to thank all colleagues from the Department of primary care for helping in data collection.

\section{Conflict of Interests}

The authors declare no conflict of interests.

\section{References}

1. Jayakumar RV (2013) Hypothyroidism and metabolic syndrome. Thyroid Res Pract 10: 1-2.

2. Ogbera AO, Kuku S, Dada O (2012) The metabolic syndrome in thyroid disease: A report from Nigeria. Indian $\mathrm{J}$ Endocrinol Metab 16: 417-422.

3. Gierach M, Gierach J, Ewerto M, Arndt A, Junik R (2014) Correlation between body mass index and waist circumference in patients with metabolic syndrome. ISRN Endocrinol 2014: 1-5.

4. Shanta G, Kumar AA, Jeyachandran V, Rajamanickam D, Rajkumar K (2009) Association between primary hypothyroidism and metabolic syndrome and the role of $\mathrm{C}$ 
reactive protein: A cross-sectional study from South India. Thyroid Res 2: 2.

5. Roos A, Bakker SJ, Links TP, Gans R, Wolffenbuttel B (2007) Thyroid function is associated with components of the metabolic syndrome in euthyroid subjects. J Clin Endocrinol Metab 92: 491-496.

6. LaFranchi S (1994) Adolescent thyroid disorders. Adolesc Med 5: 65-86.

7. Okosieme OE, Marx H, Lazarus JH (2008) Medical management of thyroid dysfunction in pregnancy and the postpartum. Expert Opin Pharmacother 9: 2281-2293.

8. Madariaga AG, Palacios SS, Guillén-Grima F, Galofré J (2014) The incidence and prevalence of thyroid dysfunction in Europe: A meta-analysis. J Clin Endocrinol Metab 99: 923-931.

9. Garduno-Garcia Jde J, Alvirde-Garcia U, Lopez-Carrasco G, Padilla Mendoza ME, Mehta R, et al. (2010) TSH and Free Thyroxine concentrations are associated with differing metabolic markers in euthyroid subjects. Eur $\mathrm{J}$ Endocrinol 163: 273-278.

10. Kapadia KB, Bhatt PA, Shah JS (2012) Association between altered thyroid state and insulin resistance. J Pharmacol Pharmacother 3: 156-160.

11. Gabriela B (2011) Why can insulin resistance be a natura consequence of thyroid dysfunction. J Thyroid Res 2011.

12. Handisurya A, Pacini G, Tura A, Gessl A, Kautzky-Willer A (2008) Effects of T4 replacement therapy on glucose metabolism in subjects with subclinical $(\mathrm{SH})$ and overt hypothyroidism (OH). Clin Endocrinol (Oxf) 69: 963-969.

13. Park SB, Choi HC, Joo NS (2011) The relation of thyroid function to components of the metabolic syndrome in Korean men and women. J Korean Med Sci 26: 540-545.

14. Erdogan M, Canataroglu A, Ganidagli S, Kulaksızoglu M (2011) Metabolic syndrome prevalence in subclinic and overt hypothyroid patients and the relation among metabolic syndrome parameters. J Endocrinol Invest 34: 488-492.

15. Lai Y, Wang J, Jiang F, Wang B, Chen Y, et al. (2011) The relationship between serum thyrotropin and components of metabolic syndrome. Endocr J 58: 23-30.

16. Kim BJ, Kim TY, Koh JM, Kim HK, Park JY, et al. (2009) Relationship between serum free T4 (FT4) levels and metabolic syndrome (MS) and its components in healthy euthyroid subjects. Clinical Endocrinol (Oxf) 70: 152-160.

17. Mohan V, Deepa M, Farooq S, Datta M, Deepa R (2007) Prevalence, awareness and control of hypertension in Chennai--The Chennai Urban Rural Epidemiology Study (CURES-52). J Assoc Physicians India 55: 326-332.

18. Park HT, Cho GJ, Ahn KH, Shin JH, Hong SC, et al. (2009) Thyroid stimulating hormone is associated with metabolic syndrome in euthyroid postmenopausal women. Maturitas 62: $301-305$

19. Uzunlulu M, Yorulmaz E, Oguz A (2007) Prevalence of subclinical hypothyroidism in patients with metabolic syndrome. Endocr J 54: 71-76.
20. Vanderpump MPJ (2005) The epidemiology of thyroid diseases. In: Braverman LE, Utiger RD, Werner and Ingbar's The Thyroid: A Fundamental and Clinical Text. JB Lippincott-Raven, Philadelphia, USA, 9: 398-406.

21. Bee YT Jr, Haresh KK, Rajibans S (2008) Prevalence of metabolic syndrome among Malaysians using the International Diabetes Federation, National Cholesterol Education Program and Modified World Health Organisation Definitions. Malays J Nutr 14: 65-77.

22. Meher LK, Raveendranathan SK, Kota SK, Sarangi J, Jali SN (2013) Prevalence of hypothyroidism in patients of metabolic syndrome. Thyroid Res Pract 10:60-64.

23. Wang JY, Wang CY, Pei D, Lai CC, Chen YL, et al. (2010) Association between thyroid function and metabolic syndrome in elderly subjects. J Am Geriatr Soc 58: 16131614.

24. Gyawali P, Takanche JS, Shrestha RK, Bhattarai P, Khanal $\mathrm{K}$, et al. (2015) Pattern of thyroid dysfunction in patients with metabolic syndrome and its relationship with components of metabolic syndrome. Diabetes Metabolism J 39: 66-73.

25. Choudhary PR, Jani RCD (2016) Study of thyroid function in patients with metabolic syndrome. Int $\mathrm{J}$ Res Med Sci 4: 2024-2029.

26. Gaurav A, Sudhakar MK, Mohini S, Senthil N, Amarbalan R (2011) The prevalence of thyroid dysfunction among South Indian women with Metabolic Syndrome. Journal of Clinical and Diagnostic Research 5: 213-216.

27. Chih-Cheng Lai, Sai-Hung Tang, Dee Pei, Cheng-Yi Wang, Yen-Lin Chen, et al. (2011) The prevalence of subclinical thyroid dysfunction and its association with metabolic syndrome in Taiwanese elderly. Int J Gerontol 5: 25-29.

28. Chih-Yuan Wang, Tien-Chun Chang, Ming-Fong Chen (2012) Associations between subclinical thyroid disease and metabolic syndrome. Endocr J 59: 911-917.

29. Tehrani FR, Tohidi M, Dovom MR, Azizi F (2011) A population based study on the association of thyroid status with components of the metabolic syndrome. J Diabetes Metab 2: 156.

30. Shrestha S, Das BKL, Nirmal Baral, Lal Chandra (2007) Association of metabolic syndrome and its components with thyroid dysfunction in females. Int $\mathrm{J}$ Diabetes Dev Countries 27: 24-26.

31. Bastemir M, Akin F, Alkis E, Kaptanoglu B (2007) Obesity is associated with increased serum TSH level, independent of thyroid function. Swiss Med 137: 431-434.

32. Meier C, Staub JJ, Roth CB, Guglielmetti M, Kunz M, et al. (2001) TSH-controlled L-thyroxine therapy reduces cholesterol levels and clinical symptoms in subclinical hypothyroidism: A double blind, placebo-controlled trial. J Clin Endocrinol Metab 86: 4860-4866.

33. Oh JY, Sung YA, Lee HJ (2013) Elevated thyroid stimulating hormone levels are associated with metabolic syndrome in thyroid young women. Korean J Intern Med 28: 180-186. 